the patient bears it well. In this case I soon abandoned it, as it caused too much discomfort. It is to be noticed that though the stitches were passed through the kidney substance, the patient had no hæmaturia (this was carefully watched for) and that no inflammation or reaction seemed to follow. But seven weeks after the operation considerable pain developed in the region of the kidney together with some albuminuria. This disappeared, however, after the use of Basham's mixture. The pain seemed to be rheumatic, and was soon relieved by the administration of salol.

\section{A CASE OF NEPHROTOMY.}

Read before the Philadelphia County Medical Society, March 27, r889. BY L. W. STEINBACH, M.D., of philadelphia.

On July I 7, I888, Mrs. Anna H., 44 years old, from New Jersey, was sent by her attending physician to my department at the Polyclinic with a statement that she had been under his care for about a month, that she presented symptoms of hepatic and gastric disorders which brought about anæmia, nervousness and irritability of the heart. She complained of indigestion, frequent vomiting of food or of mucus, attacks- of palpitation of the heart, and loss of flesh. One week ago his attention was directed to an induration in the right hypochondriac region, and, deeming it of serious import, he referred the patient to our clinic.

From her own statements and those of accompanying friends we gathered, in addition to the above, the following history :

Mrs. H. was formerly a hard working country woman, who bore six healthy children, but had had no miscarriages. She suffered in several of her confinements with puerperal mania, but considered herself in good health until eleven years ago, when, she thought, she became dyspeptic. Five years ago she noticed a lump in her abdomen, of which she made no mention to anyone until one month ago, up to which time she was able to attend to her household duties. She complains of headaches and constipation, and has not noticed any sediment in or discoloration of the urine, nor could she recall having suffered with pain that would indicate the passage of a biliary or renal calculus. Her pulse, respiration and temperature are normal, she looks anæmic, the complexion is muddy, her conversation and behavior indicate the existence of some mental weakness, the body is emaciated. Inspection shows a prominence in the right lumbar region, whilst percussion and palpitation reveal the presence of a tumor extending from the lower border of the ribs vertically for about seven inches, and, laterally, occupying the centre of the lumbar region to the extent of three inches. The percus- sion dulness is continuous with that of the right lobe of the liver. The tumor is freely moveable below, and felt through the abdominal walls imparts the sensation of a bag filled with small pebbles. Beliving that the case before me was one of a gall-bladder filled with calculi, and fearing lest manipulation would cause rupture of the cyst, I desisted from further palpation and directed my inquiries toward finding other symptoms of biliary obstruction. I drew off the urine with a catheter and submitted it to a chemical analysis, which showed the absence of albumen and the presence of some bile-pigment, No particulars of the nature of the stools could be obtained. In a letter directed to her physician, I gave it as my opinion that the patient was suffering from the effects of an enormously distended gall-bladder filled with calculi, and recommended a cholecystotomy.

One week later, she returned with the consent of her physician ready to undergo the proposed operation. After a preparatory treatment by baths, a laxative and rest in bed for two days, and after a consultation with my assistants and the physicians composing my class, in which the existing symptoms, and especially the absence of pronounced jaundice, were separately and carefully considered, I believe there was no more reserve in the minds of these gentlemen than in my own that the former diagnosis was the correct one. Dr. Keen also hastily examined the patient, concurred in the diagnosis and lent his kind assistance in the operation.

On July 26 , the patient being anæsthetized with ether, an incision three inches in length was made in the right linea semilunaris, over the most prominent portion of the tumor, beginning at the border of the ribs and dividing the abdominal muscles and peritoneum ; the apex of the tumor was reached without encountering any of the abdominal viscera. The calculi could now necessarily be felt more distinctly than before the division of the abdominal wall, and, meeting with difficulty to place the tumor on the trough-shaped apparatus devised by Dr. Keen, it was decided to pick up a fold of the cyst between two pairs of hæmostatic forceps and make an incision between the forceps, so that the calculi might be removed without permitting the escape of bile or mucus into the peritoneal cavity; this was accordingly done, and a few pieces of calculus removed, which, however, did not correspond in shape, color and general appearance to calculi of biliary origin, especially when the forceps grasped a stone evidently of large size and immovably fixed.

The idea of impacted gallstones was dispelled by the appearance of these calculi, and the thought that flashed upon the mind of every one was, that the tumor was a kidney.

The fear of rupturing the normal gall-bladder 
having suddenly vanished, the lips of the abdominal incision were drawn apart more freely, which brought to view the margin of the right lobe of the liver and a normal gall-bladder in its normal position.

Further examination showed the tumor to be the right kidney distended by several calculi of different shapes and sizes. The organ itself was twisted by being turned upon its vertical axis from behind forward and to the left, and upon its horizontal axis from above downward and from behind forward, so that the dorsal surface and the upper end presented at the anterior abdominal wall.

It was now at once decided to remove the kidney, a superficial examination indicating the existence of a kidney on the left side. The pedicle of the tumor, consisting of ureter, artery and vein, was ligated en masse with a silk cord, the kidney cut off, the abdominal incision closed with sutures and dressed. The patient was put to bed, and after half an hour came out from under the influence of the anæsthetic and inquired of the nurse about the particulars of the operation. She gave no evidence of pain or suffering. and assumed her usual air of indifference to her surroundings which, according to the statement of her niece, was her peculiarity. Three hours after the operation the bladder was catheterized, but no urine obtained. Catheterization was repeated at intervals of six hours during the two succeeding days with a like result. The temperature at 8 o'clock P. M., six hours after the operation, was $\mathrm{ror}^{\circ} \mathrm{F}$., falling to $99^{\circ}$ on the following morning, gradually rising to $103^{\circ}$ towards evening, and falling in the same manner to $100^{\circ}$ on the morning of July 28 . She slept for a few hours during the night after the operation, and after a small dose of morphia; took moderate amounts of nourishment and some stimulants. About noon of the third day began to complain of soreness all over the body, became irritable and restless, but continued to take milk and whisky. She passed no urine up to the time of her death, which occurred at 6:20 P.M., fifty-four hours after the operation, caused by suppression of urine. A post-mortem examination was not held.

The removed kidney with the calculi weighed fourteen and a half ounces, and is among the pathological specimens which Dr. Keen presents this evening.

In submitting the case for discussion and criticism of the society, without explanations in justification of the course of which I have pursued, I am adding one to the great number of recorded and unrecorded cases of movable kidney, the removal of which has been attempted or accomplished in the belief that the tumor was ovarian, uterine, splenic, or belonging to any of the abdominal or pelvic organs.

\section{A CASE OF LAPAROTOMY FOR EXTRA- UTERINE PREGNANCY. \\ A Paper read at the Allegheny County Medical Society,
March $19,1889$. \\ BY X. O. WERDER, M.D., OF PitTSBURga, PA.}

At the November meeting of this Society I reported a case of extra-uterine pregnancy in which I had performed abdominal section with a successful result. To-day I present the specimen of my second case of tubal pregnancy, removed by laparotomy, on February ifth, of this year.

The history of this case is, briefly, as follows:

Mrs. M., 27 years of age, married, two children, the youngest i 6 months old, has been suffering with periodical attacks of severe abdominal pains for almost a year, for which she several times required medical treatment. During the five or six weeks preceding the operation these attacks. increased in frequency and severity, making her unfit to do her ordinary household duties. Walking almost always produced a great deal of suffering. On January 26th, of this year, I was consulted for one of these attacks of pain, which was referred to the pelvic region, principally the left side. Making a vaginal examination, I found the uterus enlarged to the size almost of a two months' pregnancy, and to the left of this, in the region of the left tube, a soft, extremely tender mass, which was slightly movable. A careful bimanual examination could not be made on account of the very great sensitiveness of these parts. She had menstruated regularly every four weeks during the last eight or nine months, and was at this time still nursing her baby. At the two subsequent examinations I found no change in her condition, except, perhaps, that this tumor was slightly larger than before. The diagnosis was not quite clear, but I was inclined to the opinion that it was either a hydrosalpinx, or a pyosalpinx, more probably the latter. As her suffering at times had almost become unbearable, I advised laparotomy, to which she readily consented, but the operation was deferred until after her next menstrual period, which was now very close at hand. Menses lasted five days, and presented nothing unusual. In the afternnoon of the i $3^{\text {th }}$ of February, the day preceding the operation, she came to my office in a carriage, from her home, for the purpose of going to Mercy Hospital. On examination I found her condition unchanged; the mass, however, seemed now decidedly larger. The riding on the rough country road from her home did not seem to have caused her as much suffering as expected, and she was cheerful and feeling better than for several days previously. But on her way to the hospital the pains returned in unusual severity, and she arrived there faint and nearly collapsed. Several hypodermic injections of morphia made 